\title{
Engaging Student Teachers in Peer Learning via a Blended Learning Environment
}

\author{
Eugenia M. W. Ng \\ Department of Mathematics, Social Science, Science and \\ Technology, The Hong Kong In stitute of Education, \\ Hong Kong SAR
}

Eugenia@ied.edu.hk

\begin{abstract}
Teacher education, which encompasses teaching, teaching effectiveness, the factors that determine teachers' thought processes and performances, and the social policies that affect teachers in all aspects and stages of their careers, is the fundamental groundwork and primary foundation, for attemptingto undertake various innovat ive and model learning and teaching approaches. However, a number of studies have indicated that teacher education does not adequately prepare teachers to teach with technology. In light of this paradoxical situation, the author at tempted to integrate content, pedagogy and technology when teaching her post-graduate student teachers. In addition, technology was used to foster peer learning, so that participants could learn through a holistic approach in an experiential environment, rather than using technology as an add-on tool. An institutional standard questionnaire and a focus group meeting were conducted as part of this study, to gather feedback from the participants in the study, on the new learning approach, and the grades that these student teachers obtained for their individual work and group project were analyzed. It was found that the participants embraced both a peer and blended learning approach, and yet the grades that they obtained for their group projects were not superior to the grades on their individual assignments.
\end{abstract}

Keywords: blended learning, cooperative learning, information technology, online learning, peer learning, pedagogy, student teachers

\section{Introduction}

Peer learning is a kind of cooperative leaming approach, which is a two-way reciprocal learning activity (Boud, Cohen, \& Sampson, 2001).Peer learning encourages meaningful learning, which essentially involves learners teaching, as well as learning from each other. There is extensive substantiation forthe fact that peer learning involves more than just a sharing of ideas, knowledge

Material published as part of this publication, either on-line or in print, is copyrighted by the Informing Science Institute. Permission to make digital or paper copy of part or all of these works for personal or classroomuse is granted without fee provided that the copies are not made or distributed for profit or commercial advantage AND that copies 1) bear this notice in full and 2) give the full citation on the first page. It is permissible to abstract these works solong as credit is given. To copy in all other cases or to republish or to post on a server or to redistribute to lists requires specific permission and payment of a fee. Contact Publisher@InformingScience.org to request redistribution permission. and experiences. Peer learning in fact, encompasses a wide gamut of actions, wherein students intervene with their partners to correct, inform, cut off conversation, initiate play, and communicate their vision (Boud, 2001; Sinclaire, 2005). Peer learning can occur both informally and formally. Informal peer learning occurs when students discuss their assignments, lectures, and projects 
in casual social settings; whereas formal peer learning occurs when group work is explicitly required during course delivery.P eer learning has been proven to promote lifelong leaming and is linked to generic capabilities ofteamwork and interpersonal skills that employers view in a very positive light (O. S. T an, 2003).

With the rapid development of the Internet in the mid 1990s, Information Technology (IT) has presented the world a new arena for leaming and teaching, predominantly, as a bridge to facilitate peer learning. Various communication channels such as e-mails, wikis, online chats and discussion forums, provide a simple and convenient arena for a single user or for multiple users to discuss a range of subjects, asynchronously or synchronously. Internet exchanges are highly flexible and convenient as compared to other means of communication, such as face-to-face or telephone communication. Messages can be stored and retrieved easily at the discretion of users without requiring sophisticated software. Learners from different backgrounds and diverse locations can share their own learning experiences and yet generate ideas systematically, in order to provide solutions to different problems in the learning process. Lipponen (2002) has summarized how IT can enhance learning by: (1) allowing students to represent their own and others' ideas and share their expertise in text; (2) eliminat ing time and space constraints; (3) sharing discourse spaces and distributed interaction that offer multiple perspectives for students with varying knowledge and competencies, which can offer greater opport unities to share and solicit knowledge; (4) allowing time for participants to reflect through asynchronous communication; and (5) providing the database, which allows the knowledge to be shared and revisited.

The effectiveness of on-line peer collaborative learning has been confirmed by various studies. For instance, children are able to greatly increase their computer proficiency (Hyun, 2005); students can discuss varied issues in greater depth and their criticalthinking skills are considerably enhanced in the process (S. C. T an, T urgeon, \& Johansson, 2001); and learners' levels of involvement and incentives to learn have also increased significantly with a wider and more complete understanding of the subject knowledge (Eleuterio \& Bortolozzi, 2004). However, there are some who dispute this fact and opine that peer learning is just "sharing ignorance" (Sfard \& Kieran, 2001; Sinclaire, 2005) and that high achievers are not able to learn from each other (Liu \& T sai, 2008).

There are innumerable successful published cases of the use of technology to support learning. Some are for teachers for their professional development (Parr \& Ward, 2005; Treweren \& Lai, 2001); while others focus on the K-12 school context (Barron et al., 1995; Collins, Brown, \& Newman, 1989; Scardamalia \& Bereiter, 1996; Stahl, 2004; T urvey, 2006). Yet we find that not much research has been accomplished in the area of teacher education. Indeed, a number of studies have indicat ed that teacher education does not adequately prepare teachersto teach with technology (Pope, Hare, \& Howard, 2002; Selinger, 2001) and in order to successfully implement this, it is suggested that teacher education systems should integrate content, pedagogy and technology (Hughes, 2005; Koehler, Mishra, \& Yahya, 2007). In light of this glaring inadequacy, this article will discus s how to suitably integrate content, pedagogy and technology, in particular, the discussion forum of a learning plat form, to complement face-to-face learning and to support peer learning for teacher education. At the same time, a questionnaire survey will also examine whether IT can enhance learning, as proposed by Lipponen (2002), through a focus group meeting and their learning out comes. However, this article will elaborate more on the learning process rather than the learning outcomes due to the small sample size. The conclusion of the survey and fut ure research direction will be discussed at the end of the article.

\section{Integrating Content, Pedagogy, and Technology}

This study was conducted at the Hong Kong Institute of Education (HKIEd), which is the largest teacher education Institute in Hong Kong. Participants in the study were post-graduate students, 
who graduated with a Bachelor in Information Technology or equivalent degree, from other universities and were studying to obtain a Post-graduate Diploma in Education at the HKIEd. At the Institute, IT was their major teaching subject. Seven (7) full-time and two (2) part-time students were enrolled in a module entitled Supporting IT in Schools which was a core IT module.

Teaching requires good communication skills and subject knowledge; therefore it is completely inappropriateto replace regular lectures wholly, with online studies. On the other hand, there is a pressing need to model technology use in teaching and learning, in orderto enable student teachers to learn through experiential learning, especially for the selected module. A blended learning approach, which means combining face-to-face teaching and learning with online learning, was adopted so that student teachers would have an authentic learning experience of using technology to support learning and teaching. Figure 1 depicts the range of activities that were put into practice to foster blended learning, both at an individual as well as at a group level. Face-to-face interaction included standard face-to-face lectures and other classroom activities, whereas online activities included facilitating online discussion and giving feedback on the work done by their peer group.

The grades for the study were based on mainly three aspects - class participation, a group project and an individual report. The group project was connected with planning and implementing a small scale information system to support school functions, whereas the individual report was on any critical issues related to the module content. The class participation grade consisted of numerous online and face-to-face activities. Student teachers were given the freedom to choose their own group members, provided that they had only between two to four members per group. Three groups were formed, in which one group consisted of two part-time students; the second group had three members, whilst the third and final group was made up of four student teachers. For the purpose of this study, the groups are referred to as Group A, Group B and Group C respectively. Since the module in which the student teachers were enrolled, was a postgraduate module, peer leaming strat egy was also employed. Details on the integration characteristics of content, pedagogy and technology, will be elucidated in the following sub-sections.

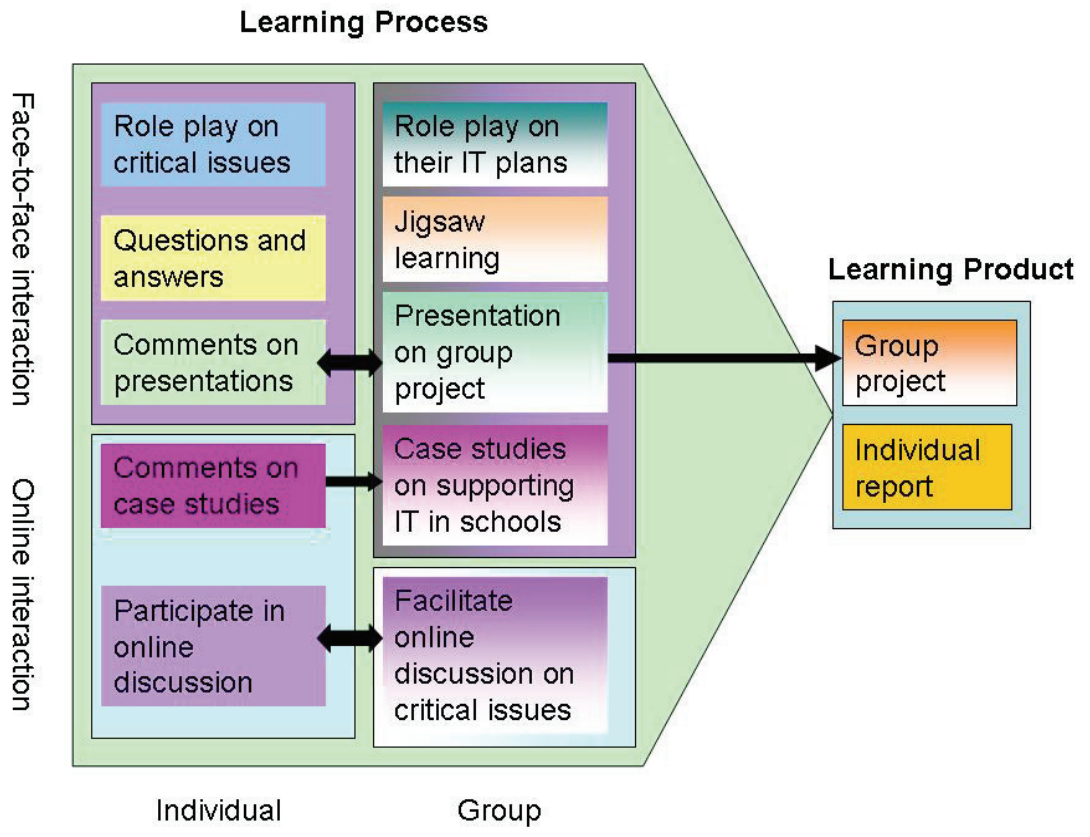

Figu re 1: A model of blended learning activities 


\section{Group Face-to-Face Activities}

The three groups had to tackle numerous case studies, for practical application of the knowledge they acquired during their lectures. The principal case the student teachers worked on was an analytical study of a fictitious school. They were instructed to work out the role of IT teachers and other staff members who might be responsible for promoting IT in schools; to design and propose an appropriate IT plan and finally outline measures forthe implementation of the said plan for the fictitious school. Due to time constraints during lessons, the groups posted their suggestions for case studies online, with the purpose of sharing information and also, for easy reference. Each group was also assigned the task of working together for their group project and also instructed to enact their IT plans. Furthermore, the student teachers participated in a jigsaw classroom method (Aronson, 2002) to learn in greater depth, about the impact of IT in different areas of education. The jigsaw classroom technique, developed in the early 1970 s, is a cooperative learning technique that promotes better learning, improves student motivation, and increases enjoyment of the overall learning experience. Each student was responsible to read a section of an essay and each piece of information is essential for the completion and full understanding of the whole essay. Therefore, each student's contribution is of crucial importance to the whole group.

\section{Individual Face-to-Face Activities}

For this section, students engaged in two role playing activities. In the first instance, student teachers had to assume the roles of senior management of HKIEd and were required to analyze the position of the Inst it ute, utilizing the "strengths, weaknesses, opportunities and threats" (SWOT) analysis approach. SWOT analysis is a commonly adopted method in the business world to analyze factors, which influence a company's compet it ive position in the market place, with the objectives of improving future performance and strengthening their market standing (Lee, Lo, Leung, \& Ko, 2000; Leskinena, Leskinena, Kurttilaa, Kangasb, \& Kajanusc, 2004; Yüksela \& Dag deviren, 2007). In the second instance, student teachers were required to enact the roles of different prominent academics in Hong Kong, who pursue and tackle critical issues such as narrowing the digital divide in Hong Kong and also, the action to be taken if a student posts some defamatory information about Teacher X on the school's discussion forum board. These role play activities not only enabled students to view issues from the perspective of a prominent personality, but also aided in fostering peer learning. The students were also encouraged to give comments for individual and group presentations, as a form of formative assessment, prior to their submissions in writing. Furthermore, they were asked occasionally to answer questions from the educat or on a variety of issues. It has been proved that role playing is an extremely valuable method for learning (Glynn, MacFarlane, Kelly, Cantillon, \& Murphy, 2006; Hayati,2006). Not only does it encourage thinking and creativity, but it also gives students an opportunity to develop and practice new language and behavioral skills, thus creating the motivation and involvement necessary for learning to occur.

\section{Group Online Activities}

Students were expected to undergo ten weeks of classroom lessons. Consequently, one of the lecture turns was scheduled on a public holiday, and it was therefore expected that a make-up class be conducted for that lecture. However, due to the students' extremely busy schedules, attending a make-up lecture was not possible. Despite this, we attempted to bridge the gap by employing technology to foster peer learning, and by asking each group to examine and analyze, what they considered, a critical and significant topic related to the module content. They were also urged to post two-three thought provoking questions for the class to discuss, based on their topic. Group A chose to analyze the role of IT coordinat ors, while Group B posted the blog of a T aiwanese teacher, confronted by the dilemma of instructing the class on the reliability of various web sites. The most 
interesting posting was from Group C, with the very thought provoking title, "Listen to our pupils." This post sought to tackle the issue of education reform and to thereby, facilitate learning from all angles. Group $\mathrm{C}$ posted all relevant background information, related links and questions for their post. The group suggested using Campus TV as a tool to facilitate learning from all angles. They also opined that asking pupils to produce self-made television programs would serve as an appropriate avenue for teachers to listen to and understand the diverse view points of their students. Group $\mathrm{C}$ agreed with the suggestions of broadcast ing self-made television programs during the recess or lunch hour, which would enable pupils to reflect on pertinent topical issues and thus sharpen their analyticalthinking process. (Details of an individual's posts and view points are explained in the next section).

\section{Individual Online Activities}

Two varieties of individual online activities were conducted, to be able to better experience the use of technology to support peer learning. Figure 2 depicts that one of the activities was to participate in the discussion hosted by peer groups, as described in the pervious section. In order to protect students' identities, their names have been blackened. The argument put forth by one student was that creating a product utilizing technology was not the sole method of getting students to listen to their teachers. He suggested that by correctly employing video or technology to record events, students would be further motivated to reflect on these events. The second online activity was to comment on the proposed solutions of the case study, as outlined in the section on Group face-to-face activities. It was ascertained that these online activities, not only facilitated peer learning, but also accorded the students much more time to reflect and correctly categorize information, to be able to support their view points.
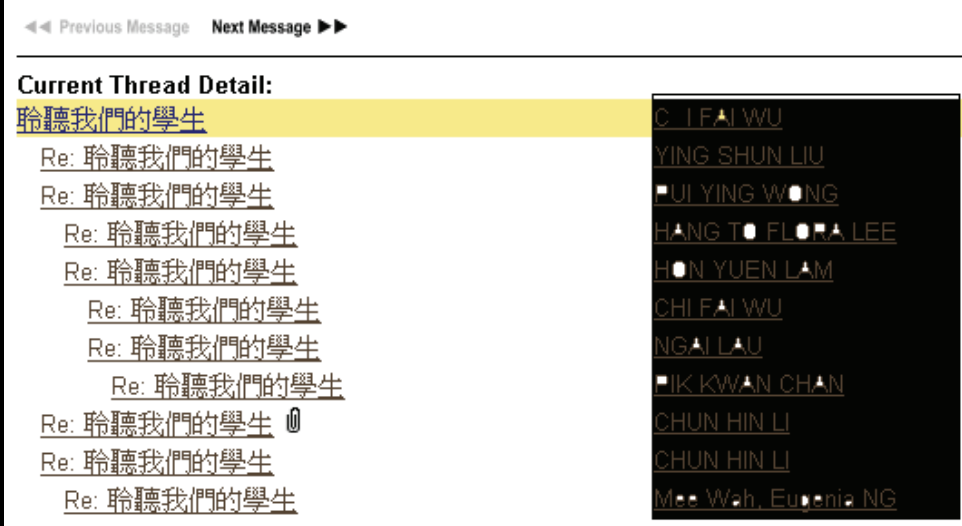

Figu re 2: A sample of an individual online discussion

\section{Findings}

It was observed that although students actively participated in all learning and teaching activities, the primary goal of this study, would be better understood, if the students shared their views and opinions, in addition to commenting on their performance. A focus group meeting where the students were encouraged to voice their thoughts and comments on the study, and a standard questionnaire of the Institute, were the two means employed for this exercise. A statistical analysis could not be executed meaningfully, due to the small sample size. It has been proved that a focus group meeting is one of the popular qualitative research methods, which encourages respondents to share their perceptions, rather than asking for general consensus (Krueger \& Casey, 2000). The 
proceeding of the meeting were recorded and transcribed by a research assistant. In the interests of objectivity, we sought to compare the group performance with individual performance.

\section{Learners' Achievements}

Table 1 demonstrates that that the grades that the student teachers obtained for their individual essay were similar to the grades for their group projects. The findings revealed that they cooperated and worked together on the project, rather than permitting the more competent students in their group, to handle additional project work.

Table 1: Relation ship between in dividual and grou p assessmen ts

\begin{tabular}{|l|l|l|l|}
\hline Group & No of Mem bers & $\begin{array}{c}\text { Grades O btained } \\
\text { (Group Work) }\end{array}$ & Grades O btained (In di vidual Work) \\
\hline A & 2 & B & B, C+ \\
\hline B & 3 & A- & A-, A, B+ \\
\hline C & 4 & B & B+, B+, C+, B- \\
\hline
\end{tabular}

\section{Learners' Evaluations}

There were 8 respondents for the module evaluation and the response rate was $88 \%$. The questionnaire comprised of a 4-point Likert Scale graded on a scale of strongly disagree, disagree to agree and strongly agree. Although the Institute's questionnaire solicited a limited amount of information, it was obvious that the student teachers in the study adopted a wi de range of learning and teaching activities, as shown in Figure 3. Item 3 - "The coursework helped me to develop the knowledge and skills identified in the module objectives," hadthe highest mean of 3.5, followed by Item 4 - "The learning activities stimulated my interest in the subject," and Item 5 - "The learning activities of the module also inspired me," both of which had the mean of 3.38. The only it em that received a lower rating (2.8) was, "I was fully informed of the assessment requirements early in the module."

\section{Learners' Comments}

Students were asked to participate in a focus group meeting, which would seek their opinions, on the subject of using blended learning and peer learning approaches. Seven out of nine post graduate students attended this focus group meeting. On the topic of peer learning, they opined that peer learning was positive and served a valuable purpose. This study was in reality, the first time that they actually experienced peer learning, as a part of the entire learning process. They divided and shared responsibilities according to their individual strengths, and nat urally exchanged and discussed ideas, as a group. When the students were asked to give an example of good peer learning, one of the students firmly believed that the role play activities actually motivat ed them to learn.

"We could find more ways to improve when we discussed together." Another student volunteered the information that the jigsaw classroom learning approach was excellent, as they could understand an article after it was explained by the others in the group, and yet they saved valuable time, by not having to read the entire article on their own. One of the full-time students articulated his opinion on the fact that when the students presented their group project, they observed that it was particularly beneficial, when the part-time students shared theirthoughts, as they did not have any prior teaching experience. 


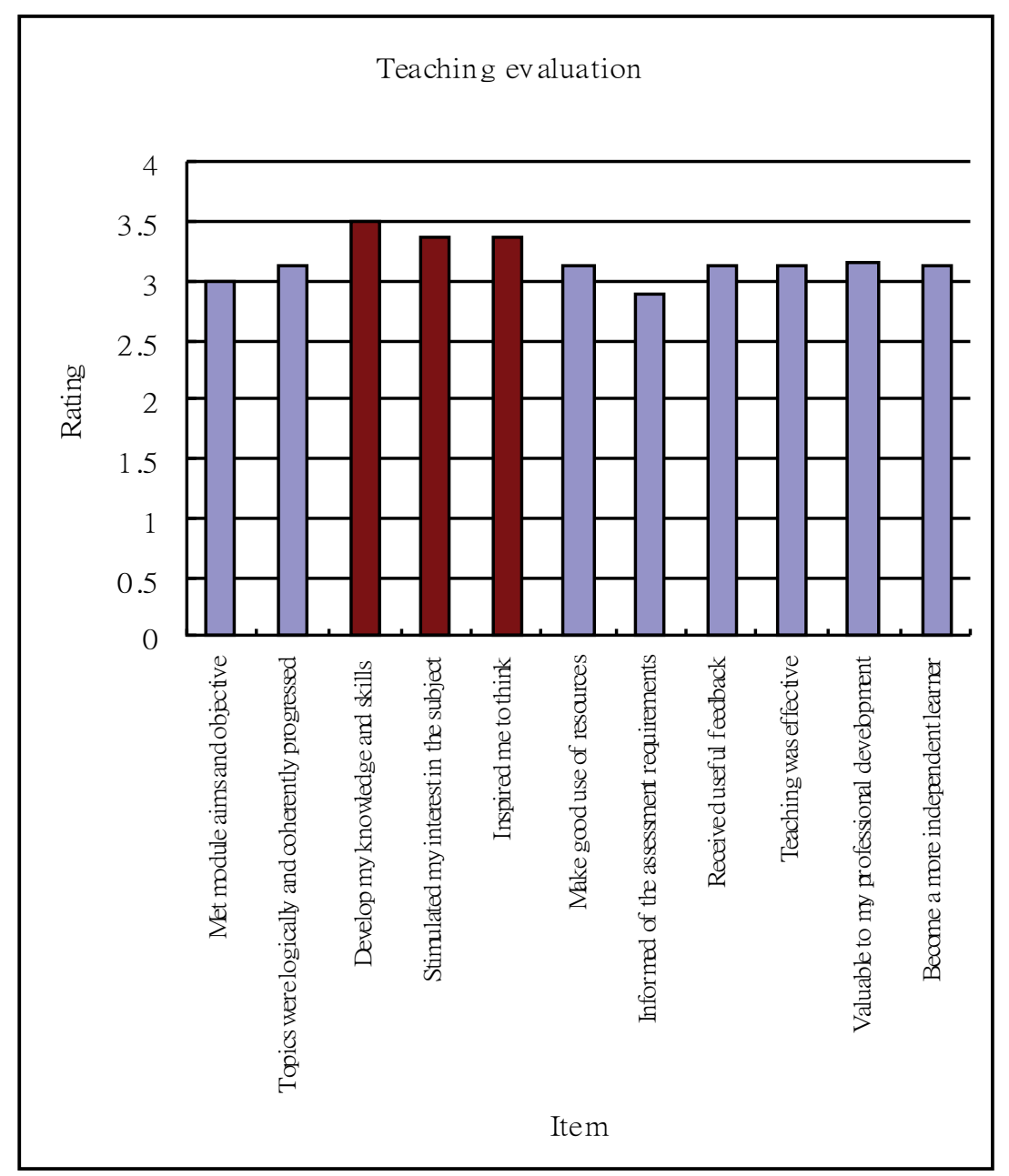

Figu re 3: Teaching evaluation

However, it was noted that all the students in the study possessed experience from preceding online activities. Upon being asked for examples of advantageous online activities, the students cited the following: 1) reading and comprehending information from web-sites of other schools, on IT learning act ivities. This enabled them to compare and better apprehend their progress and development in the field, vis-à-vis other schools; (2) another case in point was the activity, wherein each group posted questions on a critical issue, which was then thrown open for discussion by the other groups; and (3) a final case for online work was made, when the students unanimously declared that they had more time to continue unfinished class work after classes and then post it on the discussion forum for sharing.

When questioned about using Information Technology to support learning, one of the participants concluded that, "We hadmore time to think and to prepare responses before we posted anything on the discussion forum. Therefore, the information was more accurate than in face to face discussions." Yet another participant stat ed that, "Peer leaming is more relaxing as we are more open in our communication. We are able to benefit greatly from receiving feedback and information posted by our classmates." The final and ult imate endorsement for the use of IT to support learning came from the student teacher who believed that online discussions were so beneficial, that he suggested saving all the discussion forum postings in a file, for fut ure easy referral by all students. 


\section{Limitations of the Study}

There were limitations to this study and generalization should be interpreted with care. Firstly, the results gathered from this study cannot be statistically substantiated due to the small sample size.

Secondly, there was only one individual assignment and one group project to make the comparison between grades obtained individually versus as a group. As a result, the interpretation and analysis of the findings was based more on data collected qualitatively.

\section{Conclusion and Future Research Directions}

This study discusses how best to int egrate content, pedagogy and technology to foster peer learning for student teachers at the HKIEd. The superior ratings accorded by the student teachers to the questionnaire, implied that they found the activities conducted for the study, both stimulating and inspiring fortheir work. Comments from a focus group meeting also confirmed that they appreciated peer learning more than individual learning. Participants very collectively embraced the use of discussion forums as a learning platform to complement face-to-face learning and to support peer learning forteacher education. However, their learning outcomes indicated that they performed similarly as a group or as an individual. The findings suggested that student teachers embraced the learning process as much as the learning product. In conclusion, it was noteworthy that the findings of the study not only matched the five advantages of using IT to enhance learning, as proposed by Lipponen (2002), but also emphatically succeeded in promoting peer learning.

We acknowledge that the different activities that our student teachers participated in were only an initial opport unity for them to experience peer and blended learning. The future direction of this research includes: (1) incorporat ing peer learning act ivities into different modules of the teacher education program, so that the momentum achieved by this study, can be maintained; (2) re-examining current assessment methods and criteria. Specifically, the criteria should include cooperative skills and IT competency so that teachers, students, parents and employers at large, would have a better understanding of individuals' abilities and capacities; and (3) longitudinal research to examine whether IT is a good medium for fostering peer learning.

\section{Acknowledgments}

The author is very thankful to all learners for participating and giving insightful comments for this study. Special thanks for Mike Keppel for initiating the project, Mavis Ho for organizing and transcribing the focus group meet ings and Roxanna Shroff for editing effort.

\section{References}

Aronson, E. (2002). Building empathy, compassion and achievement in the jigsaw classroom. San Diego, Calif: Academic Press.

Barron, B., Vye, N. J., Zech, L., D, S., Bransford, J. D., Goldman, S. R., et al. (1995). Creating contexts for community-based problem solving: The Jasper challenge series. In C. Hedley, P. Antonacci \& M. Rabinowitz (Eds.), Thinking and literacy: The mind at work (pp. 47-72). Hillsdale, NJ: Lawrence Erlbaum Associates.

Boud, D. (Ed.). (2001). Introduction: Making the move to peer learning. London: Kogan

Boud, D., Cohen, R., \& Sampson, J. (Eds.). (2001). Peer learning and assessment. London: Kogan

Collins, A., Brown, J. S., \& Newman, S. (1989). Cognitive apprenticeship: Teaching the crafts of reading, writing, and mathematics. In L. Resnick (Ed.), Knowing, learning, and instruction (pp. 453-494). Englewood Cliffs, NJ: Lawrence Erlbaum Associates. 
Eleuterio, M. A., \& Bortolozzi, F. (2004). AMANDA: An intelligent systems for meditating threaded discussions. International Journal on Elearning, 3(3), 13-21.

Glynn, L. G., MacFarlane, A., Kelly, M., Cantillon, P., \& Murphy, A. W. (2006). Helping each other to learn - a process evaluation of peer assisted learning. Retrieved 08 March 2008, from http://www.biomedcentral.com/bmcmededuc? page $=9 \&$ relevant $=$ true .

Hayati, M. (2006). Take 2, Act 1: Feeding tow birds with one scone! The role of role-playing in teaching English. Arts and Humanities in Higher Education, 5(2), 209-219.

Hughes, J. E. (2005). The role of teacher knowledge and learning experi ences in forming technology-integrated pedagogy. Journal of Technology and Teacher Education, 13(2), 377-402.

Hyun, E. (2005). A study of 5- to 6-year-old children's peer dynamics and dialectical learning in a computer-bas ed technology-rich cl assroom environment. Computers \& Education, 44, 69-91.

Koehler, M., Mishra, P., \& Yahya, K. (2007). Tracing the development of teacher knowledge in a design seminar: Integrating content, pedagogy and technology. Computers \& Education, 49(3), 740-764.

Krueger, R. A., \& Casey, M. A. (2000). Focus Groups: A Practical Guidefor Applied Research (3rd ed.). Thousand Oaks, Calif: Sage Publications

Lee, S. F., Lo, K. K., Leung, R. F., \& Ko, A. S. O. (2000). Strategy formulation framework for vocational education: Integrating SWOT analysis, balanced scorecard, QED methodology and MBNQA education criteria. Managerial Auditing Journal, 15(8), 407-423.

Leskinena, L. A., Leskinena, P., Kurttilaa, M., Kangasb, J., \& Kajanusc, M. (2004). Adapting modern strategic decision support tools in the participatory strategy process-A case study of a forest research station. Forest Policy and Economics, 8(3), 267-278.

Lipponen, L. (2002). Exploring foundations for computer-supported collaborative learning. Retrieved 20 March, 2007, from http://www.helsinki.fi/science/network edlearning/texts/lipponen2002.pdf

Liu, C. C., \& T sai, C. C. (2008). An analysis of peer interaction patterns as discoursed by on-line small group problem-solving activity. Computers \& Education, 50(3), 629-639.

Parr, J. M., \& Ward, L. (2005). Creating online professional learning communities: A case of cart before horses. In K.-W. Lai (Ed.), e-learning Communities: Teaching and learning with the web (pp. 125-134). Dunedin: University of Otago Press.

Pope, M., Hare, D., \& Howard, E. (2002). Technology integration: Closing the gap between what preservice teachers are taught to do and what they can do. Journal of Technology and Teacher Education, 10(2), 191-203.

Scardamalia, M., \& Bereiter, C. (1996). Engaging students in a knowledge society. Educational Leadership, 54(3), 6-11.

Selinger, M. (2001). Learning information and communications technology skills and the subject context of the learning. Journal of Information Technology for Teacher Education, 10(1\&2), 143-154.

Sfard, A., \& Kieran, C. (2001). Cognition as communication: Rethinking learning-by-talking through multi-faceted an alysis of students' mathematical interactions. Mind, Culture, and Activity, 8(1), 42-76.

Sinclaire, M. P. (2005). Peer interactions in a computer lab: Reflections on results of a case study involving web-bas ed dynamic geometry sketches. Journal of Mathematical Behavior, 24, 89-107.

Stahl, G. (2004). Building collaborative knowing - elements of a social theory of CSCL. In J. W. Strijbos, P. A. Kirschner \& R. L. Martens (Eds.), What we know about CSCL (pp. 53-85). Boston, Mass: Kluwer Acad emic Publishers.

Tan, O. S. (2003). Problem-based learning innovation: Using problems to power learning in the 21st century. Singapore: Thomson Learning. 
Tan, S. C., Turgeon, A. J., \& Johansson, D. H. (2001). Develop critical thinking in group problem solving through computer-supported collaborative argumentation: A case study. Journal of Natural Resources and Life Sciences Education, 30, 97-103.

Treweren, A., \& Lai, K.-W. (2001). Online learning: An alternative way of providing pro fessional development for teachers. In K.-W. Lai (Ed.), e-learning Teaching and professional development with the Internet (pp. 37-55). Dunedin: University of Otago Press.

Turvey, K. (2006). Towards deeper learning through creativity within online communities in primary education. Computers \& Education, 46, 309-321.

Yüksela, İ., \& Dag deviren, M. (2007). Using the analytic network process (ANP) in a SWOT analysis - A case study for a textile firm. Information Science, 177(16), 3364-3382.

\section{Biography}

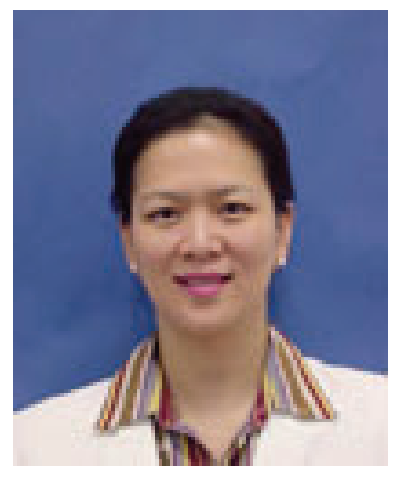

Dr. Eugenia $\mathbf{~ N g}$ is an associate professor and Information T echnology Division Head in the Mathematics, Science, Social Sciences and Technology Department of the Hong Kong Institute of Education. She has been a research investigat or of various internal and external funded projects. She has had over seventy articles published in conference proceedings, journals, newspapers and as book chapters. She is the associate editor of International Journal of Web-based Learning and Teaching Technologies and Advances in Web-based Learning (AWBL) Book Series, a member of the editorial board of Annals of Cases on Information Technology, and reviewers for Journal of Computers in Human Behavior and Journal of Interactive Learning Research. She is also an associate supervisor of a doct oral student at Queensland University. 